\title{
TRANSFIKSASI AKAR FI'IL TSULATSI MUJARROD BAHASA ARAB
}

\author{
Oleh : Tadkiroatun Musfiroh
}

\begin{abstract}
Abstrak
Seiring dengan pengakuan adanya transfiks bahasa Arab dalam dunia linguistik dewasa ini, yakni afiks yang dilekatkan pada morfem akar belah, permasalahan afiksasi tersebut juga mulai dibahas dalam bukubuku linguistik Indonesia. Meskipun demikian, transfiks yang diulas masih terlalu umum dan hanya sebentuk, yakni $\{-a-a-a\}$. Bentuk yang dibahas juga hanya Konsonan-a-Konsonan-a-Konsonan-a atau CaCaCa seperti darasa dan kataba, atau bahkan $\mathrm{CaCaC}$ seperti katab dan daras. Padahal, apabila dicermati, transfiks dalam bahasa Arab tidak sesederhana itu, karena terdapat dalam berbagai kasus dan dalam berbagai bentuk.

Oleh karena itu, dalam tulisan ini akan dicoba bahas permasalahan afiks belah yang melekat pada morfem akar belah tersebut, walaupun pembahasannya hanya dibatasi pada transfiks yang melekat pada morfem akar belah dasar (asli) tiga konsonan kerangka berkategori verba atau fi'il tsulatsi mujarrod, meliputi verba lampau atau fi'il madli dan verba kekinian/keakanan atau fi' il mudhori.

Berdasarkan telaah sederhana terhadap verba-verba berakar belah tiga dari tiga konsonan atau C-C-C- dan verba-verba berakar belah dua dari tiga konsonan atau C-CC-, ditemukan tiga buah transfiks yang melekat pada $C-C-C$ - dan satu buah transfiks yang melekat pada $C$ CC-. Transfiks-transfiks tersebut adalah $\{-a-a-a\}$ seperti dalam jalasa

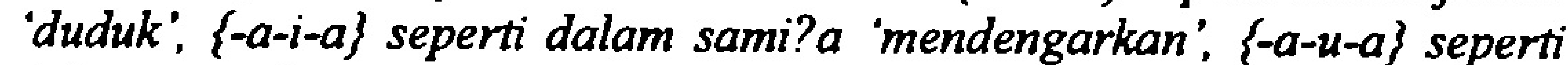
dalam saru?a 'cepat', dan \{-a-a\} seperti dalam Sabba 'menegak (minum)'. Transfiks-transfiks tersebut merupakan transfiks yang berbeda, bukan alomorf dari salah satu bentuk di antaranya. Hal itu dibuktikan dengan pasangan minimal dan pengkonsultasian ke bentuk fi'il mudhorinya. Transfiks-transfiks tersebut dilekatkan untuk membentuk verba transitif dan verba intransitif. Untuk memudahkan pengecekan, disertakan sumber data contoh, yakni, kamus Al-Munawwir (kode M), dan kamus Mahmud Yunus (kode Y). Angka di belakang kode menunjukkan halaman sumber buku tersebut.
\end{abstract}

\section{A. Pendahuluan}

Semua bahasa di dunia memiliki aspek keunikan dan keuniversalan. 
Artinya, setiap bahasa memiliki hal-hal umum yang dimiliki oleh setiap bahasa, namun juga memiliki kekhasan yang mungkin hanya ada dalam bahasa itu sendiri. Satu hal yang dimiliki oleh hampir semua bahasa di dunia adalah proses morfologis dengan afiksasi atau pengimbuhan afiks.

Bahasa Arab, sebagai bagian dari bahasa-bahasa di dunia, juga mengenal proses morfologis dengan afiksasi. Di antara bentuk afiks yang ada adalah sufiks, prefiks, dan transfiks. Sufiks dan prefiks merupakan afiks yang umum dimiliki oleh banyak bahasa, tetapi bentuk afiks transfiks merupakan afiks yang khas dan dominan dalam pembentukan kata bahasa Arab.

Transfiksasi dalam bahasa Arab terjadi pada hampir seluruh kata dan kasus. Di antaranya adalah transfiksasi pada kata kerja atau verba. Verba bahasa bahasa Arab sendiri mengalami transfiksasi karena adanya penanda kala, pelaku, perubahan kategori, dan sebagainya. Perubahan yang terjadi oleh sementara ahli dimasukkan ke dalam kategori modifikasi internal. Misal, di antara bentuk kataba, kataba:, katabta, dan infleksinya termasuk konjugasi, yang dinyatakan sebagai morfem dasar adalah kataba. Kalau dilihat sepintas, memang pendapat tersebut dapat dibenarkan. Walaupun demikia, apabila kita merujuk langsung ke dalam sistem pembentukan kata bahasa Arab, hal tersebut tidak dapat dibenarkan bahkan dinilai terlalu tergesa-gesa. Apalagi jika sampai dinyatakan bahwa bentuk dasarnya berpola $\mathrm{CaCaCa}$ saja, tentu kaidah itu akan mengingkari bentuk lain seperti ?alima 'mengetahui' (CaCiCa), Haruma 'terlarang' ( $\mathrm{CaCuCa})$, dan sejenisnya.

Seperti diketahui dan diakui, kata-kata dalam bahasa Arab tidak dibentuk dari morfem pangkal seperti kataba, ?alima, dan Haruma (meminjam istilah Verhaar), tetapi dibentuk dari morfem yang berupa akar belah (lihat Bauer, Verhaar, dan Chaer) atau konsonan kerangka (istilah Matthews). Dengan demikian, bentuk-bentuk seperti ?alima, Haruma, dan kataba, yang dianggap morfem dasar bukanlah morfem dasar. Bentuk-bentuk itu merupakan derivan karena telah mengalami proses morfologis.Bentuk-bentuk tersebut bahkan dapat dikatakan telah mengandung penanda kala lampau dari verba aktif, sedangkan bentuk dasamya adalah k-t-b-, ?-l-m-, dan H-r-m-. Bentukbentuk tersebut selamanya membutuhkan afiks berupa vokal-vokal. Konsonan kerangka pembentuk morfem akar belah tersebut seringkali mengalami penambahan yang kadang dikacaukan dengan konsonan kerangka dasarnya.. 
Karena alasan-alasan tersebut, perlu kiranya memperkenalkan dan mengulas permasalahan transfiksasi itu secara lebih mendalam. Sebab, selain penting dan menarik, permasalahan transfiksasi tersebut baru disentuh-bahas dalam lingkup kecil sebagai contoh dalam buku-buku pengantar linguistik dewasa ini.

\section{B. Pembahasan}

\section{Morfem Belah : Morfem Dasar dan Transfiks}

Bentuk-bentuk seperti kataba, darasa, ?alima, dan Haruma bukanlah morfem dasar. Bentuk-bentuk tersebut merupakan derivan yang dibentuk dari morfem akar $k-t-b-, d-r-s-$, ?-l-m-, dan $H-r-m-$ dengan afiksasi. Morfem akar, yang dalam bahasa Inggris dikenal dengan istilah "root", merupakan morfem dasar yang tidak dapat berdiri sendiri dan tidak dapat dianalisis ke dalam bentuk yang lebih kecil lagi (Bauer, 1988:252). Sebagai bentuk dasar yang terikat, morfem akar seperti $d-r-s-, \quad k-t-b-, \quad ?-l-m-$, dan $H-r-m-$, selalu membutuhkan imbuhan agar menjadi bentuk bebas (Verhaar, 1997:99).

Morfem akar, terbagi atas dua macam, yakni morfem akar belah dan morfem akar utuh. Morfem akar dalam bahasa Latin am- yang dapat dibentuk menjadi amare, merupakan contoh morfem akar utuh, sedangkan morfem akar konsonan kerangka bahasa Arab $d-r-s-, k-t-b$ - yang dapat dibentuk menjadi darasa dan kataba merupakan contoh morfem akar belah. Kedua morfem akar tersebut selamanya membutuhkan afiks, dan tidak dapat langsung menyatu dengan klitik, pengulangan, ataupun pemajemukan.

Kata-kata dalam bahasa Arab, umumnya terdiri atas morfem-morfem belah. Satu morfem belah berkedudukan sebagai morfem dasar dan satu morfem lainnya berkedudukan sebagai imbuhan. Kedua morfem tersebut saling terikat untuk membentuk konstruksi bebas. Morfem dasar yang terdiri atas konsonan kerangka disebut morfem akar belah, dan morfem belah yang melekati morfem akar belah tersebut dikenal dengan istilah transfiks.

Istilah transfiks dibedakan dari istilah konfiks. Walaupun keduanya merupakan afiks belah, morfem dasar yang dilekatinya berbeda. Konfiks adalah afiks belah yang dilekatkan pada stem atau dasar pangkal dan pradasar, 
sedangkan transfiks menurut Bauer (1988:255-256), adalah "discontinous morphs which are interspersed throughout the bases with their occur". Transfiks, menurut Chaer (1994:181), berwujud vokal-vokal yang diimbuhkan pada keseluruhan dasar yang biasanya berupa konsonan-konsonan.

Meskipun banyak ahli bahasa yang pada awalnya menolak konsep transfiks tersebut, Bauer tetap konsisten dengan pendapatnya. Kilani-Schoch \& Dressler (1984) misalnya, menganggap istilah transfiks sebagai hasil analisis yang keliru. Ia menegaskan bahwa analisis yang tepat untuk kasus dalam bahasa Arab itu adalah modifikasi internal atau modifikasi internal ganda. Matthews (1978:131), bahkan menyebutnya sebagai morfem diskontinyus biasa atau konfiks. Ahli-ahli lain bahkan tidak menyinggungnya sama sekali. Meskipun demikian, dalam buku-buku linguistik terakhir, banyak ahli bahasa yang mengutip dan membenarkan analisis Bauer. Meskipun mereka tidak jelasjelas menyebutnya sebagai transfiks, tetapi konsep yang mereka ikuti mengenai transfiks terpampang dalam buku-buku tulisan mereka.

Lebih lanjut, Bauer menjelaskan bahwa transfiks dibentuk dari sejumlah vokal yang dilekatkan pada operan yang terdiri atas konsonankonsonan kerangka. Posisi transfiks yang satu berbeda dengan transfiks yang lain. Sebuah transfiks mungkin dilekatkan pada operan akar yang mengandung klaster, sedangkan yang lain tidak. Transfiks yang lain bahkan mungkin mempunyai posisi yang tetap pada akar (Bauer, 1988:24). Apabila diperhatikan, pendapat Bauer tersebut tidak bertentangan dengan aturan dan kenyataan pembentukan kata dalam bahasa Arab. Seperti diketahui, salah satu pemodusan dalam bahasa Arab adalah dengan harakat, yakni dengan dlommah ( 2-), fathah ( $:$ ), kasrah ( - ), sukun ( $:$ ), dan huruf hijaiyah. Selain itu, penetapan transfiks $\{-a-a-a\}$ saja, seperti kataba, jalasa, darasa, membuat permasalahan baru, sebab masih terdapat transfiks lain selain bentuk transfiks tersebut. Di samping itu, bentuk-bentuk tersebut dapat dikatakan men gandung persona berkala lampau (Thatcher, 1956:61).

\section{Fi'il dan Fi'il Tsulatsi Mujarrod}

Fi'il dalam pengertian lingustik sama dengan verba, yakni lafadz atau bentuk-bentuk yang menunjukkan terjadinya suatu pekerjaan pada waktu tertentu (Irbabullubab, 1970:6). Verba dalam bahasa Arab terdiri atas verba 
bentuk lampau atau $f i^{\prime} i l$ madli, verba bentuk kekinian/keakanan atau $f i^{\prime} i l$ mudhori, imperatif atau fi'il amr (Anwar,1996:49-50). Verba-verba tersebut, walaupun mengandung kala, biasanya hadir atau lekat bersama personanya, yakni pelaku yang mengerjakan verba. Verba dan verba berpersona dalam bahasa Arab terdiri atas verba dengan morfam akar belah konsonan dasar dan tambahan, dan konsonan dasar tiga dan empat. Agar lebih jelas, perhatikan contoh-contoh berikut ini.

1a. aslama 'menyelamatkân'

2a. inkasarO 'pecah'

3a. istaghfarO 'memohon ampun'

4a. tadahwarO 'jatuh

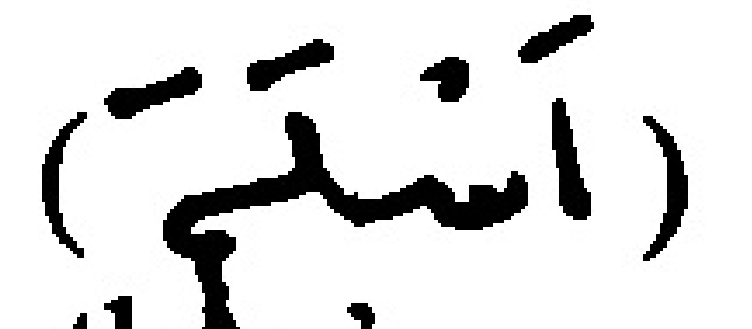<smiles>[14CH3]</smiles>

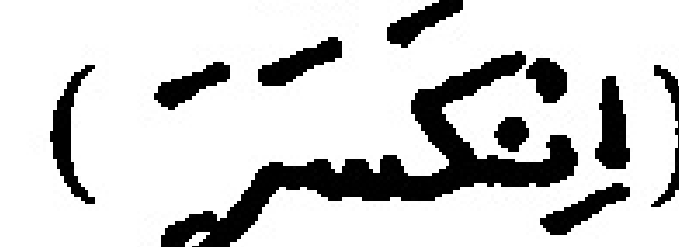

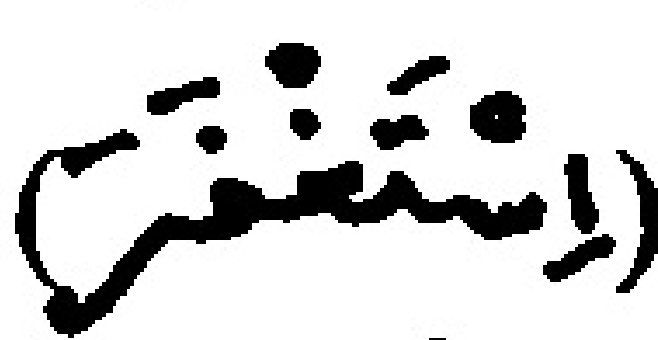

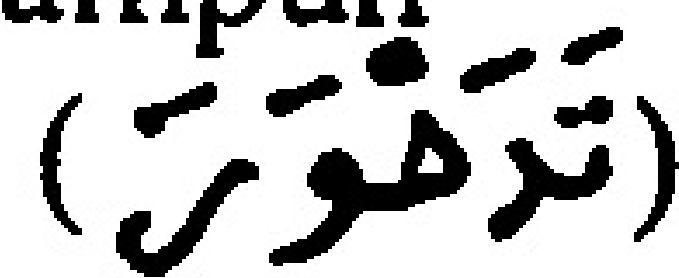

Kalau diperhatikan, konsonan kerangka pembentuk verba-verba di atas bervariasi jumlahnya. Ada verba yang terdiri atas tiga konsonan seperti s-l-mpada salima, k-s-r-pada kasarO, gh-f-r pada ghofarO, empat konsonan seperti 's-l-m pada aslama, d-h-w-r- pada dahwarO, lima konsonan seperti '-n-k-s-r pada inkasarO, t-d-h-w-r pada tadahwarO, dan bahkan enam konsonan seperti '-s-t-gh-f-r pada istaghfarO. Meskipun demikian, verba-verba tersebut, berdasarkan konsonan kerangka pembentuknya, dapat digolongkan ke dalam beberapa kategori.

(1) Di antara verba-verba tersebut di atas, terdapat verba yang konsonan pembentuknya dapat dipilah menjadi konsonan sebagai morfem akar belah dasar dan konsonan sebagai unsur tambahan (lihat 1a, 2a, 3a, 4a, ). Verba dengan ciri-ciri demikian disebut $f i$ 'il mazid.

(2) $\mathrm{Di}$ antara verba-verba tersebut, terdapat verba-verba yang konsonan pembentuknya merupakan morfem akar belah dasar atau asli/ bukan tambahan, artinya kehadiran konsonan-konsonan tersebut pokok dan tidak dapat dihilangkan, sebab penghilangan terhadap salah satu konsonan pembentuknya akan menghilangkan makna yang dikandungnya. 
Konsonan kerangka dalam verba-verba tersebut merupakan dasar pembentukan kata-kata yang lain. Verba-verba yang mempunyai konsonan semacam itu ( lihat contoh $1 \mathrm{~b}, 2 \mathrm{~b}, 3 \mathrm{~b}, 4 \mathrm{~b}$, ) disebut fi'il mujarrod.

(3) Di antara fi'il mujarrod atau verba dengan morfem akar belah konsonan asli tersebut, terdapat verbal yang dibentuk dengan tiga konsonan dasar dan ada pula verba yang dibentuk dengan empat konsonan dasar. Fi' $i l$ mujarrod yang dibentuk dengan tiga konsonan dasar seperti contoh $1 \mathrm{~b}, 2 \mathrm{~b}$, dan $3 \mathrm{~b}$, disebut $f i$ 'il tsulatsi mujarrod. Sedangkan fi'il mujarrod yang dibentuk dengan empat konsonan dasar seperti contoh $4 \mathrm{~b}$, disebut $f i^{\prime} i l$ ruba'i mujarrod.

\section{Transfiks pada Fi'il Tsulatsi Mujarrod}

Transfiks yang melekat pada akar fi'il tsulatsi mujarrod, apabila diperhatikan, memiliki berbagai bentuk. Transfiks pada verba bermorfem akar belah dasar tersebut tidak hanya terdiri atas tiga vokal kembar -a-a-a seperti yang dicontohkan dalam buku-buku linguistik dewasa ini, seperti darasa 'membaca', jalasa 'duduk', fataHa 'membuka, dan kataba 'menulis', tetapi meliputi juga dua vokal lain dalam bahasa Arab. Seperti diketahui, bahasa Arab hanya mengenal vokal [a] dengan alofon [O] pada konsonan tertentu, [I], dan [u]. Ketiga vokal [a], [I], dan [u] tersebut terlibat dalam proses transfiksasi. Hal itu dibuktikan dalam $f i$ 'il tsulatsi mujarrod berikut ini.

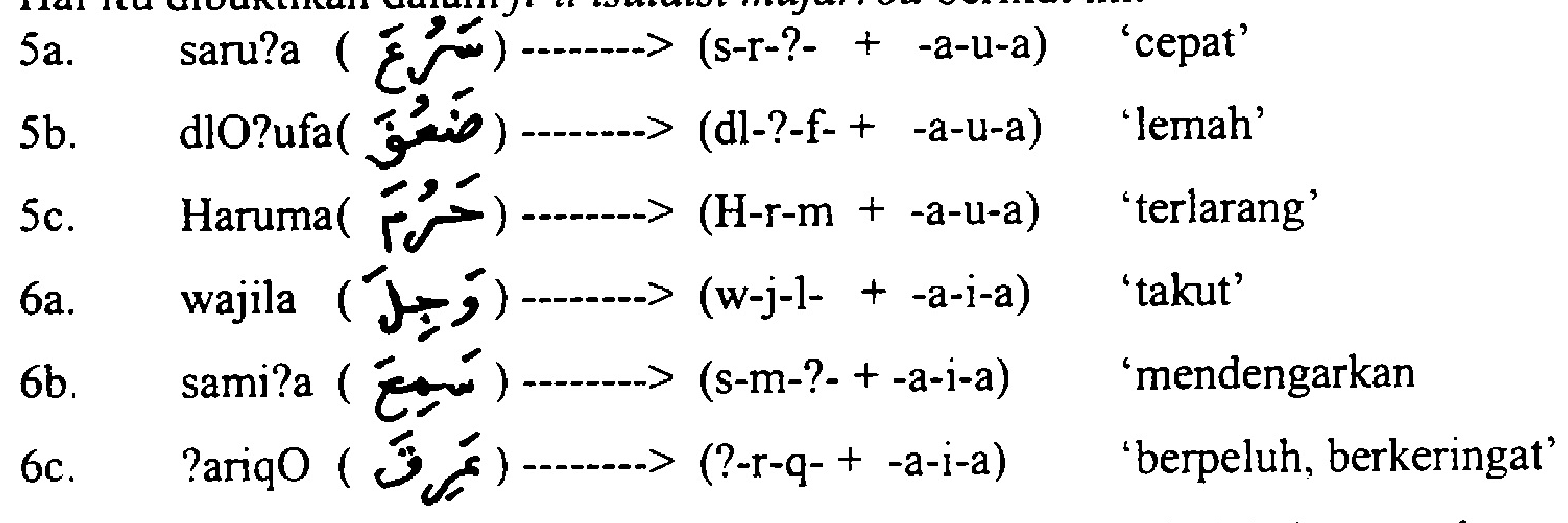

Dengan mencermati contoh di atas, dapat diketahui bahwa terdapat verba dengan bentuk $\mathrm{CaCuCa}$ seperti saru?a, dlO? ufa, Haruma, dan terdapat pula verba dengan bentuk $\mathrm{CaCiCa}$ seperti wajila, sami?a, ?ariqO. Hal ini memperkuat dugaan adanya bentuk transfiks selain $\{-\mathrm{a}-\mathrm{a}-\mathrm{a}\}$, yakni $\{-\mathrm{a}-\mathrm{u}-\mathrm{a}\}$ 
seperti contoh 5a, 5b, dan 5c, dan $\{-\mathrm{a}-\mathrm{i}-\mathrm{a}\}$ seperti contoh $6 \mathrm{a}, 6 \mathrm{~b}$, dan $6 \mathrm{c}$. Keberadaan transfiks-transfiks tersebut kadang diragukan karena ditemukan bentuk dlo? if 'lemah' di samping dlo?ufa, sama? 'mendengar' di samping sami? a, dan Haram 'yang dilarang' di samping Haruma. Orang kemudian menganggap transfiks-transfiks tersebut hanyalah alomorf dari salah satu bentuk yang paling luas distribusinya, yakni transfiks $\{-\mathrm{a}-\mathrm{a}-\mathrm{a}\}$. Meskipun demikian, pendapat tersebut dapat dinilai tergesa-gesa, karena tidak memperhatikan adanya derivasi dalam bahasa Arab serta kurang memperhatikan contoh-contoh lain dengan morfem akar dasar yang sama tetapi dilekati transfiks yang berbeda.

Argumentasi bahwa terdapat transfiks $\{-\mathrm{a}-\mathrm{a}-\mathrm{a}\},\{-\mathrm{a}-\mathrm{u}-\mathrm{a}\}$, dan $\{-\mathrm{a}-\mathrm{i}-\mathrm{a}\}$ dalam khasanah afiks bahasa Arab, dapat dibuktikan dengan menampilkan pasangan minimal bagi tiap-tiap bentuk dengan memakai morfem akar dasar yang sama dan yang belum mengalami perubahan apapun, seperti contoh berikut ini. Untuk memudahkan pengecekan disertakan pula sumber data, yakni kamus Muhammad Yunus (kode Y) dan kamus Al-Munawwir (kode M). Angka di belakang kode menunjukkan nomor halaman buku tersebut.

7a . Hasaba (حَ) 'menghitung'----.--> H-s-b- + -a-a-a (Y.102)

7b. Hasuba (حَ) 'mulia' --.---.-> H-s-b- + -a-u-a (Y. 102; M. 261)

7c. Hasiba (حَبَبَ) 'mengira' -------.> H-s-b- + -a-i-a (Y. 102; M. 261)

8a. jalada (كَ) 'memukul' -...--..-> j-1-d- + -a-a-a

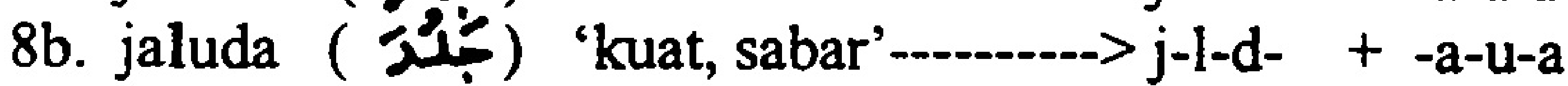

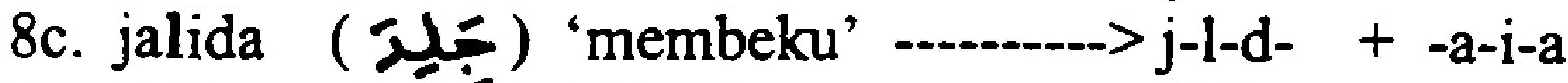

9a. faHama (كَ) 'tidak kuasa --..--..--> f-H-m- + -a-a-a

9b. faHuma (فَ) 'menjangis -.-.-...-> f-H-m- + -a-u-a

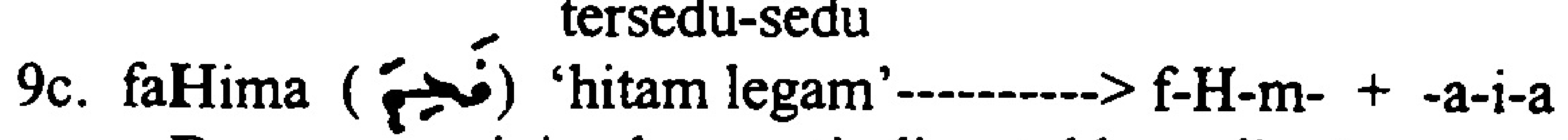

Pasangan minimal seperti dicontohkan di atas, membuktikan bahwa perbedaan vokal di tengah membedakan arti verba tersebut. Dengan demikian, pendapat bahwa $\{-\mathrm{a}-\mathrm{u}-\mathrm{a}\}$ dan $\{-\mathrm{a}-\mathrm{i}-\mathrm{a}\}$ merupakan alomorf dari $\{-\mathrm{a}-$ a-a\} tidak dapat dibenarkan. Meskipun demikian, diakui bahwa transfiks \{-a-aa) merupakan transfiks yang paling luas distribusinya dalam fi'il tsulatsi mujarrod. Bukti tersebut sekaligus menggugurkan pendapat Matthews (1978: 
131), bahwa bentuk afiks dalam morfem akar dasar tersebut adalah $\{-\mathrm{a}-\mathrm{a}\}$ dan $\{-\mathrm{i}-\mathrm{i}\}$, seperti dalam katab 'menulis' dan fihim 'memahami', karena setelah dilakukan pengecekan, transfiks bentuk $\{-\mathbf{a}-\mathrm{a}\}$ tidak terdapat dalam morfem akar belah C-C-C, tetapi terdapat dalam morfem akar dasar C-CC- seperti dalam contoh berikut ini.

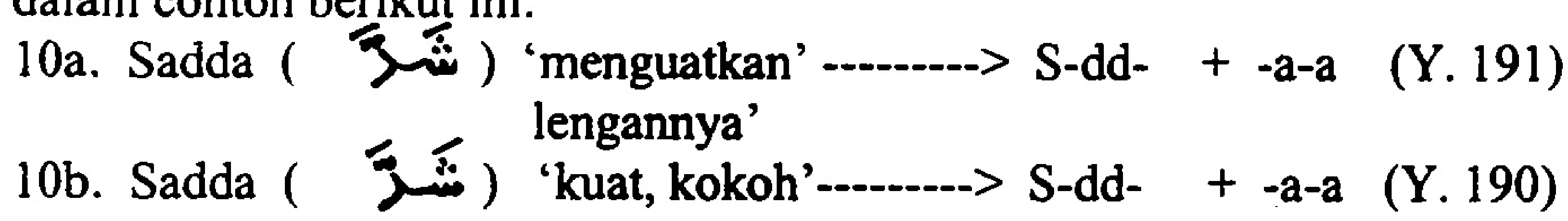

Selain itu, transfiks bentuk $\{-\mathrm{i}-\mathrm{i}\}$ yang dinyatakan oleh Matthews dalam bukunya, tidak ditemukan dalam buku ataupun kamus yang membicarakan dan mencantumkan fi'il tsulatsi mujarrod. Meskipun demikian, transfiks $\{-a-a\}$ yang dipergunakan untuk mengecek pendapat Matthews (lihat contoh 10a dan 10b), justru dapat digunakan untuk memperkaya khasanah transfiks yang telah ditemukan oleh para ahli nahwu sharaf. Seperti diketahui, ahli nahwu sharaf telah mencermati bentuk fi'il tsulatsi mujarrod dan mengakui adanya verba-verba dengan kaidah $\mathrm{CaCaCa}$ seperti kataba dan darasa, $\mathrm{CaCuCa}$ seperti saru? a dan Haruma, $\mathrm{CaCiCu}$ seperti sami?a dan wajila. Sayangnya, bentuk $\mathrm{CaCCa}$ tidak disinggung, walaupun bentuk dengan kaidah tersebut (lihat kembali contoh 10a dan 10b) dikenal dan diakui keberadaannya. Memang, pada mulanya bentuk-bentuk seperti sadda-sadda ditengarai sebagai bentuk pemendekan dari sadada-sadada. Namun dalam perkembangannya, bentuk sadda lebih dikenal dan bentuk sadada tidak lagi digunakan. Bahkan apabila dikonsultasikan ke bentuk mudhorinya, transfiks tersebut tidak mengalami penzeroan seperti transfiks $\{-\mathrm{a}-\mathrm{a}-\mathrm{a}\}$ dalam $\mathrm{CaCaCa}$. Dengan demikian, terhadap pendapat yang menyatakan bahwa terdapat modifikasi internal dari $\mathrm{CaCaCa}$ ke bentuk lain dalam verba-verba di atas juga perlu diragukan, karena makna verba akibat perubahan vokal-vokalnya tidak memiliki kaitan makna sama sekali dengan bentuk yang dipilih sebagai bentuk dasar.

Lebih lanjut, pendapat mengenai adanya transfiks $\{a-a-a\},\{-a-i-a\}$, \{-a-u-a\}, dan $\{-\mathrm{a}-\mathrm{a}\}$ dalam khasanah afiks bahasa Arab dapat dijelaskan dengan menyertakan perubahan vokal transfiks pada fi'il madhorinya. Seperti diketahui, contoh-contoh yang disuguhkan di depan merupakan contoh fi'il madli atau verba lampau, dan apabila diubah ke dalam verba kekinian/ 
keakanan, vokal-vokal pada transfiks yang berbeda mungkin akan berbeda pula perubahannya, walaupun morfem akar dasarnya sama.

\begin{tabular}{|c|c|c|}
\hline \multirow{4}{*}{$\begin{array}{l}\text { Akar } \\
\text { j-l-d- }\end{array}$} & F.Madli & F..Mudhori \\
\hline & jalada & yajlidu \\
\hline & jalida & yajladu \\
\hline & jaluda & yajludu \\
\hline \multirow[t]{3}{*}{$\mathrm{H}-\mathrm{s}-\mathrm{b}-$} & Hasaba & aHsubu \\
\hline & Hasiba & yaHsibu \\
\hline & Hasuba & yaHsubu \\
\hline \multirow[t]{2}{*}{$\mathrm{f}-\mathrm{H}-\mathrm{m}$} & faHama & yafHamu \\
\hline & faHima & yafHamu \\
\hline \multirow{2}{*}{ S-dd- } & Sar & yatHumu \\
\hline & Sadda & yaSiddu \\
\hline
\end{tabular}

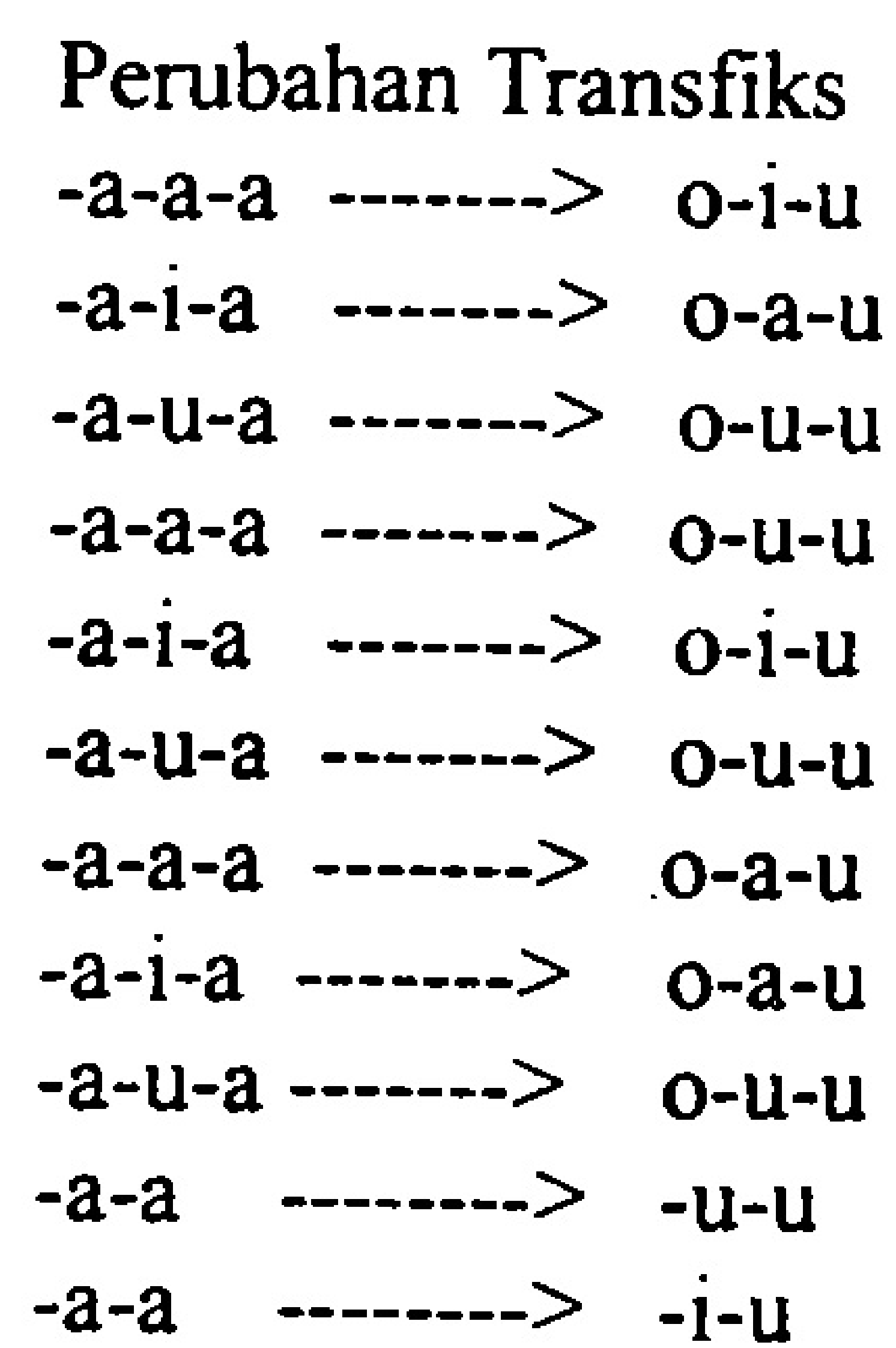

Dengan memperhatikan perubahan vokal transfiks tersebut, dapat diketahui bahwa vokal-vokal pada transfiks yang berbeda apabila dilekatkan pada morfem akar belah dasar yang sama dapat mengalami perubahan vokal yang berbeda seperti pada jalada, jalida, jaluda, dan pula mengalami perubahan yang sama seperti Hasaba, Hasuna, faHama, faHima. Sebaliknya, transfiks yang sama apabila dilekatkan pada morfem akar dasar yang berbeda dapat mengalami perubahan vokal yang berbeda seperti pada jalada, Hasaba, faHama, dan dapat pula mengalami perubahan vokal yang sama seperti pada jaluda, Hasuba, dan faHuma. Contoh tersebut dapat lebih diperjelas dengan keterangan berikut.

(1) Sermua vokal awal pada transfiks (-a-a-a, -a-i-a, -a-u-a, ) fi'il tsulatsi mujarrod pada fi'il madli, setelah memperoleh afiks ya (s) fi'il mudhori, vokal tersebut lesap atau tidak muncul, dan akibatnya muncul tanda mati (" ).

(2) Seluruh vokal akhir pada transfiks fi'il tsulatsi mujarrod fi'il madli (a-a-a, -a-i-a, -a-u-a, dan -a-a) berubah menjadi vokal [u] setelah memperoleh afiks ya ( $\mathbf{s})$ pada fi' il mudhori. 
(3) Vokal tengah pada transfiks fi'il tsulatsi mujarrod fi'il madli (-aa-a, -a-u-a, -a-i-a), setelah memperoleh afiks ya (ي) pada fi'il mudhori mengalami beberapa perubahan. Jika vokal tengah tersebut [a], pada $f i$ 'il mudhori berubah menjadi [u] seperti pada Hasaba-yaHsubu, berubah menjadi [I] seperti pada jalada-yajlidu, dan tetap [a] seperti pada faHama-yafHamu. Jika vokal tengah tersebut [I], pada fi'il mudhori berubah menjadi [a] seperti jalida-yajladu dan tetap [I] seperti pada Hasiba-yaHsibu. Apabila vokal tengah tersebut [u], pada fi'il mudhori tidak mengalami perubahan.

(4) Transfiks $\{-a-a\}$ juga mengalami perubahan vokal dari fi'il madli ke fi'il mudhori, yakni vokal awal pada transfiks $\{-\mathbf{a}-\mathbf{a}\}$ pada fi'il tsulatsi mujarrod, berubah menjadi [u] atau [I] pada fi'il mudhorinya seperti dalam Sadda-yaSuddu, Sadda-yaSiddu. Perubahan vokal dari awal [a] menjadi [u], dan [a]-[I] lebih umum dan dominan daripada [a]-[a]. Hal ini dikarenakan bentuk Sadda sebenarnya berasal dari Sadada, rOqqo berasal dari $r O q O q O$. Fi'il-fi'il tersebut mengalami perangkapan karena proses pemendekan dari dua huruf hijaiyah yang berdekatan. Dalam perkembangannya, bentuk pendek tersebut sudah lazim dan diterima, sehingga transfiks $\{-a-a\}$ juga diakui sebagai bentuk transfiks tersendiri, dan mempunyai kaidah sendiri bila dikonsultasikan ke fi'il mudhori.

Penjelasan tersebut, apabila dibuat kaidah transfiksasi akar fi'il tsulatsi mujarrod dan perubahan vokalnya setelah memperoleh afiks pada fi'il mudhori, akan menjadi sebagai berikut.

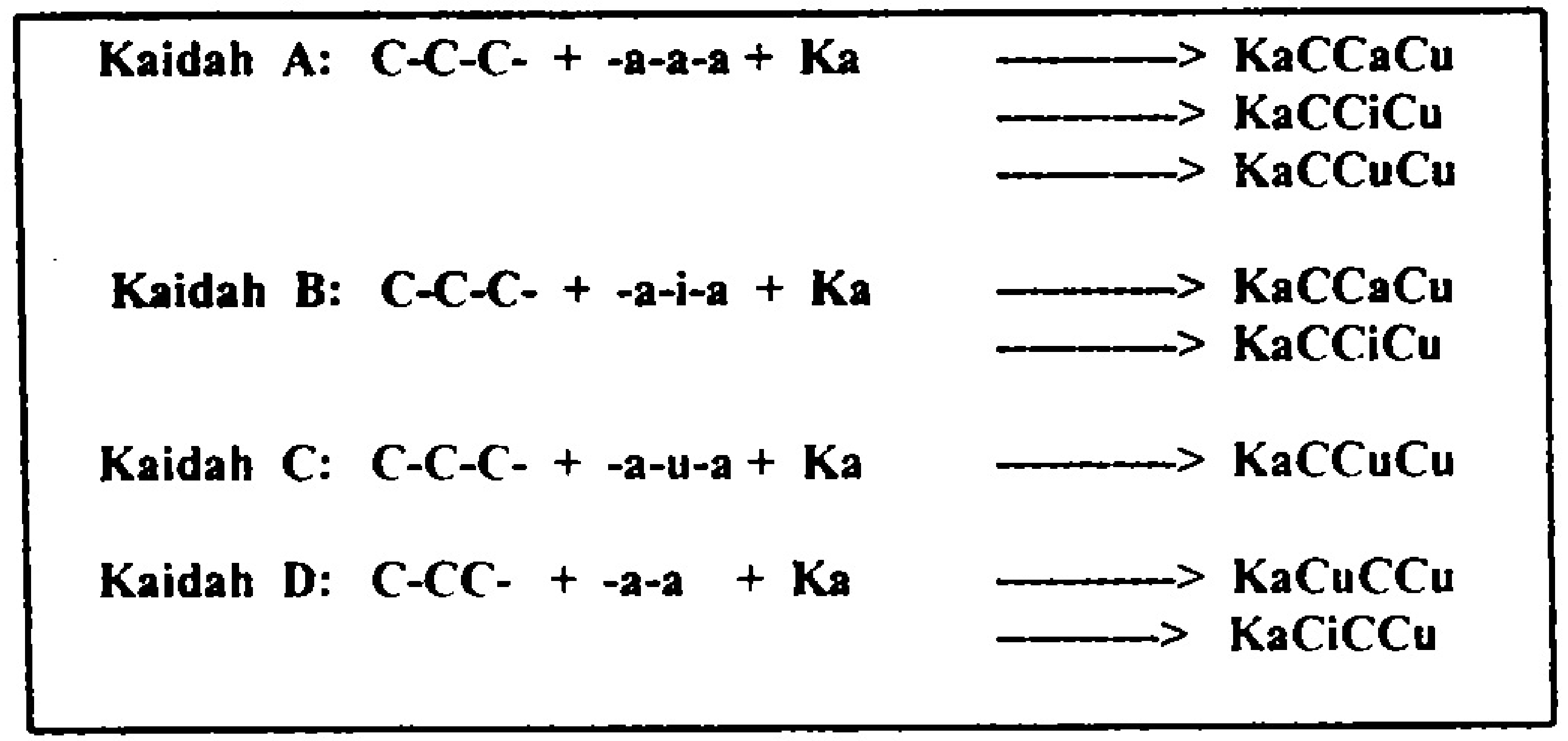


Apabila diperhatikan, transfiks-transfiks pada morfem akar belah dasar dalam fi'il tsulatsi mujarrod bahasa Arab tersebut berfungsi untuk membentuk verba yang meliputi verba transitif seperti HadarO 'melarang', rOsama 'menggambar', dan verba intransitif seperti jalasa 'duduk', rOqOda 'tidur'. Meskipun demikian, seperti dikatakan oleh Thatcher (1956: 6l) perlu dicermati bahwa konsep verba dalam bahasa Arab meliputi verba itu sendiri ( makna seperti yang terdapat dalam kamus) dan verba yang telah mengandung kala dan persona pelaku. Dengan demikian, adakalanya pembaca kamus perlu mencermati arti kata fi'il tsulatsi mujarrod yang tertulis dalam kamus agar dalam pemakaiannya tidak serta-merta menerapkannya secara sebarang konteks.

\section{Simpulan dan Saran}

Berdasarkan pembahasan tersebut di atas dapat dibuat simpulan sebagai berikut.

Dalam fi'il tsulatsi mujarrod terdapat proses pembubuhan afiks yang dilekatkan pada morfem akar belah C-C-C- dan C-CC-yang disebut transfiks. Transfiks tersebut terdiri atas empat bentuk, yakni $\{-\mathrm{a}-\mathrm{a}-\mathrm{a}\},\{-\mathrm{a}-\mathrm{u}-\mathrm{a}\},\{-\mathrm{a}-\mathrm{i}-$ a\}, dan $\{-a-a\}$. Keempat transfiks tersebut adalah transfiks yang berbeda. Hal itu dibuktikan dengan pasangan minimal dan pengkonsultasian langsung ke bentuk fi il mudhori. Walaupun transfiks $\{-a-a\}$ pada mulanya berasal dari transfiks $\{-a-a-a\}$, dalam perkembangan selanjutnya, bentuk tersebut diakui sebagai transfiks tersendiri.

Vokal-vokal transfiks pada f'il tsulatsi mujarrod mengalami perubahan setelah dikonsultasikan ke fi'il mudhori. Morfem akar dasar C-C-C+ transfiks -a-a-a $+\mathrm{Ka}$ menjadi $\mathrm{KaCCaCu}, \mathrm{KaCCiCu}$, dan $\mathrm{KaCCuCu}$. Morfem akar dasar C-C-C- + transfiks -a-u-a menjadi $\mathrm{KaCCuCu}$, dan morfem akar dasar C-C-C- + transfiks -a-i-a menjadi $\mathrm{KaCCaCu}$ dan $\mathrm{KaaCCiCu}$. Morfem akar dasar C-CC- hanya bisa dilekati transfiks -a-a, dan dalam $f i$ 'il mudhori menjadi $\mathrm{KaCuCCu}$ dan $\mathrm{KaCiCCu}$. Transfiks-transfiks tersebut berfungsi untuk membentuk verba, yang meliputi verba transitif dan verba intransitif.

Mengingat pentingnya pembicaran tentang morfologi bahasa Arab dan masih jarangnya perhatian terhadapnya, diharapkan para pecinta bahasa mulai "melirik" bidang ini. 


\section{DAFTAR PUSTAKA}

Anwar, Mochammad. 1986. Ilmu Nahwu. Bandung : Sinar Baru.

Bauer, Laurie. 1988. Introducing Linguistic : Morphology. Edinburgh : Edinburgh University Press.

Bybee, Joal L. 1985. Morphology: A Study of The Relation between Meaning and Form. Amsterdam: John Benjamins Publishing Company.

Chaer, Abdul. 1994. Linguistik Umum. Jakarta: Rineka Cipta.

Chrystal, David. 1985. A Dictionary of Linguistics and Phonetics. New York: Basil Blackwell.

Irabullubab. 1970. Nahwu dan Sharaf (I-VI). Semarang : Toha Putra.

Kridalaksana, Harimurti. 1984. Kamus Linguistik. Jakarta : Gramedia. 1989. Pembentukan Kata dalam Bahasa Indonesia. Jakarta: Gramedia.

Matthews, P.H. 1978. Morphology: An Introduction to The Theory of WordStructure. Cambridge: Cambridge University Press.

Munawwir, Ahmad Warson. 1977. Kamus Arab-Indonesia Al-Munawwir. Surabaya: Pustaka Progressif.

Sudaryanto. 1988. Metode Linguistik: Metode dan Aneka Teknik Pengumpulan Data. Yogyakarta: Gadjah Mada University Press.

1993. Metode dan Teknik Analisis Bahasa: Pengantar Penelitian Wahana Kebudayaan secara Linguistik. Yogyakarta: Duta Wacana University Press. 
Samsuri. 1982. Analisis Bahasa. Jakarta: Erlangga.

Thatcher, G. W. 1956. Arabic Grammar of Written Language. London: Perci Lund, Humpries \& Co. Ltd.

Verhaar, J.W.M. . 1997. Azas-azas Linguistik Umum. Yogyakarta : Gadjah Mada University Press.

Yunus, Mahmud. 1989. Kamus Arab-Indonesia. Jakarta: Hidakarta Agung. 